\title{
JÓVENES DOCTORANDOS EUROPEOS Y LATINOAMERICANOS EN BARCELONA: EXPERIENCIAS MIGRATORIAS Y VIVENCIAS EN LA CIUDAD
}

\author{
ANNA ORTIZ \\ Cristóbal MendozA²
}

\begin{abstract}
RESUMEN - La literatura sobre migraciones internacionales ha estudiado sólo parcialmente la migración de estudiantes, que se apunta como uno de los flujos migratorios más relevantes del actual momento de diversidad de patrones migratorios mundiales. Menos exploradas han estado incluso las cotidianidades de este colectivo y su relevancia para entender los patrones de migración futura. Este artículo intenta llenar ese espacio en la literatura y se centra en el análisis de un colectivo de estudiantes extranjeros de doctorado en varias universidades de Barcelona. En particular, analiza sus motivos para emigrar, sus trayectorias laborales y vitales, sus espacios cotidianos, así como sus visiones del futuro. La experiencia de residir en el extranjero se vive como un punto de no retorno en las transiciones de este grupo de jóvenes hacia la vida adulta y la independencia. El artículo explora este proceso complejo de emancipación del hogar familiar en relación con las prácticas y experiencias espaciales cotidianas. En este sentido, la ciudad de Barcelona permite usos variados del espacio público que facilitan cotidianidades y experiencias personales alternativas.
\end{abstract}

Palabras clave: Jóvenes estudiantes de doctorado; migración calificada; técnicas visuales; Barcelona.

AbStraCt - Young Phd students from Europe and Latin America in BarceLONA: MIGRATION EXPERIENCES AND EVERYDAY PRACTICES IN THE CITY. Literature on international migration has partially studied student migration, which is seen as an outstanding migration flow in the current age of hypermobility. Even less explored is the study of the everyday experiences of this group and its relevance for understanding students' future

Recebido: Janeiro 2015. Aceite: Abril 2016.

1 Profesora de la Universitat Autònoma de Barcelona, Facultad de Letras, Departamento de Geografía, 08193 Bellaterra, Barcelona, España. E-mail: anna.ortiz@uab.cat

2 Profesor de la Universidad Autónoma Metropolitana-Iztapalapa, División de Ciencias Sociales y Humanidades, Departamento de Sociología, Av. San Rafael Atlixco, 186, Colonia Vicentina, Delegación Iztapalapa, 09340 Ciudad de México, México. E-mail: cmp@xanum.uam.mx 
migration patterns. This article fills a gap in the literature, and it focuses on the analysis of a group of foreign PhD students in Barcelona's universities. Specifically it revolves around their motivations for emigration, everyday experiences in the city, as well as labour and life trajectories in the light of future expectations. Living abroad is regarded as a point of no return in young people's transitions towards independence and adulthood. The paper explores the complex process of leaving home in relation with their everyday spatial practices and experiences. In this regard, their everyday lives in Barcelona opens up previously unexpected personal choices, with the city offering many personal potentialities concerning alternative uses of public places.

Keyworks: Young PhD students; skilled migration; visual methods; Barcelona.

RÉSUMÉ - Les JeUnes doctorants EURopéEns ET LATINO-AmÉRICAINS À BARCELONE: EXPÉRIENCES MIGRATOIRES ET LEUR VIE À LA VILLE. La littérature sur les migrations internationales n’a que partiellement étudié celle des étudiants, qui apparait comme l’un des plus importants flux migratoires à léchelle globale. Moins explorées encore ont été les pratiques quotidiennes de ce groupe et leur importance pour la compréhension des futurs modèles de migration. On essaie de combler cette lacune en se concentrant sur l'analyse d'un groupe de doctorants étrangers dans diverses universités de Barcelone. On analyse en particulier leurs raisons démigrer, leurs parcours professionnels et personnels, leurs espaces quotidiens et leurs visions d'avenir. Vivre à létranger est vécu par ce groupe de jeunes comme un point de non-retour, lors de leur transition vers lâge adulte et l'indépendance. On montre la complexité des processus démancipation du foyer familial, en ce qui concerne les pratiques spatiales quotidiennes. En ce sens, la ville de Barcelone permet des usages très divers de lespace public, qui facilitent des expériences personnelles quotidiennes alternatives.

Mots clés: Jeunes doctorants; migration qualifiée; techniques visuelles; Barcelone.

\section{INTRODUCION}

La mayoría de estudios sobre movilidad relacionan el aumento de los desplazamientos con la globalización y la integración económica mundial (Castles \& Davidson 2000; Stephen, 2007; Smith \& Bakker, 2008). ${ }^{i}$ La facilidad de contacto y de comunicación entre diferentes puntos del planeta ha comportado además el replanteamiento teórico de la migración pensada como un proceso unidireccional, entre un punto de salida y otro de llegada, que ya no implicaría automáticamente un proceso de adaptación/integración/ asimilación en una sociedad de destino. En este sentido, por ejemplo, Smith (2001), propone el concepto "urbanismo transnacional", en cuanto el sentido de interconectividad transnacional permite combinar la distancia física y la movilidad con las posibilidades de reconstruir relaciones sociales en ámbitos geográficos concretos separados espacialmente. Además, es evidente que muchos de los desplazamientos que se realizan en este mundo cada vez más integrado responden a razones que no se podrían calificar, al menos de forma automática, como "económicas"; por ejemplo, el turismo, los procesos de reagrupación familiar o los desplazamientos por estudio (Favell, 2008). 
A pesar del reconocimiento de nuevas formas de movilidad en el mundo contemporáneo, e incluso el nacimiento del "paradigma de las nuevas movilidades" en el marco de la sociología británica (por ejemplo, Sheller \& Urry, 2006; Urry, 2007), las investigaciones empíricas que abordan colectivos concretos, sus problemáticas y sus pautas de inserción social son escasas (Favell, 2001). En este sentido, los estudiantes constituyen un colectivo que, de forma creciente, se está desplazando a nivel mundial, a pesar de que es una de las categorías de migrantes menos estudiadas (King \& Ruiz-Gelices, 2003; King \& Raghuram, 2013). En el contexto actual de globalización y de internacionalización de los sistemas educativos, los estudiantes internacionales forman un grupo de migrantes que se desplazan atraídos por distintas razones a universidades europeas (Staniscia, 2012), siendo las relaciones sociales de amistad y parentesco razones determinantes para que los jóvenes decidan estudiar en el extranjero (Beech, 2015). La movilidad geográfica mejora el capital humano de los estudiantes (Baláz \& Williams, 2004) y es, en sí misma, una forma de capital que se convierte en capital económico en el momento de entrar el mercado laboral (Leung, 2013). En principio, son migrantes esperados y deseados porque traen consigo habilidades y conocimientos que desarrollan en los países de destino (Raghuram, 2013) y pueden establecer interrelaciones socioculturales (Waters \& Brooks, 2011), al margen de la entrada de dinero que aporta este colectivo a las arcas de las universidades. Los estudiantes internacionales pueden llegar a ser también agentes urbanos que contribuyen a cambios morfológicos, económicos y sociales en el paisaje urbano de determinadas ciudades (Collins, 2010).

En esta línea, este artículo analiza un grupo de personas que ejemplifican la diversidad creciente de los patrones contemporáneos de migración internacional: un colectivo de personas jóvenes que están realizando estudios de doctorado en universidades de Barcelona. Su perfil de movilidad, intuimos, es complejo, en el sentido de que estas personas se han desplazado a la ciudad por un período de tiempo amplio, de más de un año, durante el cual realizarán unos estudios considerados cruciales en su desarrollo profesional, tanto es así que la finalización exitosa de estos estudios está asociada a un ascenso profesional en el mundo universitario (y también son valorados por las empresas privadas). Probablemente debido a que su migración está acotada, en principio, a un período de su vida, la vinculación con el país de origen puede no sufrir una ruptura traumática. Es más, es previsible que la relación y los vínculos con el país de origen sean fluidos y la movilidad periódica.

Los ejes centrales de nuestra investigación giran en torno a las motivaciones y expectativas de movilidad de estos jóvenes, sus transiciones laborales y personales, la concepción de la migración como un paso decisivo para consolidar una apuesta profesional determinada y el papel de la ciudad de Barcelona como lugar de atracción de estas migraciones. En concreto, respecto a este último punto, analizamos el uso y apropiación del territorio y el espacio, en el marco de una migración temporal. El hecho de que estas migraciones sean consideradas temporales, en momentos vitales que, en muchos casos, corresponden a procesos formativos, implica potencialidades y restricciones diferenciadas a los de su lugar de origen, de tal forma que las cotidianidades de estos "migrantes" pueden verse liberadas en un territorio nuevo "de transición". Este territorio puede per- 
mitir relaciones sociales, usos del tiempo y del espacio "alternativos", aunque también restricciones inherentes a un nuevo espacio urbano y social, que puede ser ajeno a este colectivo. Con algunas excepciones (Conradson \& Latham, 2005; Wiles, 2008), este aspecto que se quiere abordar en el artículo ha sido, por último, poco explorado en los estudios de migración internacional, que han ignorado, en gran medida, los aspectos cotidianos y geográficos que construyen comunidades migrantes en más de un estado-nación.

De esta manera, el análisis de las vivencias de este colectivo de estudiantes en Barcelona constituye el argumento principal en torno al cual se organiza este artículo. A partir del análisis de sus experiencias vitales urbanas, se reflexiona sobre la relevancia que tienen las características sociodemográficas y las trayectorias migratorias de los estudiantes a la hora de analizar cómo estas vivencias inciden o se interrelacionan con otras formas de entender su cotidianidad a partir del hecho de ser estudiantes, extranjeros y hombre/ mujer. Esta reflexión en torno a las cotidianidades urbanas servirá también para entender los recorridos migratorios futuros del colectivo que actualmente está realizando estudios de postgrado. Esta visión es ciertamente innovadora dado que los estudios de migración internacional han priorizado los aspectos laborales a la hora de comprender las trayectorias migratorias de las personas.

Una vez enmarcada teóricamente la investigación, presentaremos los principales resultados de ésta. En primer lugar, se explican las técnicas cualitativas utilizadas y el perfil de las personas entrevistadas. En segundo lugar, se presentan los principales resultados de las entrevistas realizadas a un grupo de jóvenes doctorandos europeos y latinoamericanos, abordándose las razones por las cuales estos jóvenes decidieron en su momento migrar a Barcelona, la percepción que tienen de la etapa vital que están viviendo, sus cotidianidades en la ciudad de Barcelona, así como sus proyectos migratorios futuros. Para complementar estos resultados, se muestra el análisis de las fotografías realizadas por las personas entrevistadas y los mapas mentales elaborados por ellas mismas de la ciudad de Barcelona. Por último, se exponen las reflexiones finales.

\section{TÉCNICAS CUALITATIVAS UTILIZADAS Y PERFIL DEL GRUPO ENTREVISTADO}

Se optó por la entrevista semi-estructurada como la técnica más adecuada para explorar la complejidad de las subjetividades de los jóvenes doctorandos, así como sus experiencias migratorias y vida cotidiana en Barcelona. En total, se entrevistó a 23 personas (14 mujeres y 9 hombres) entre finales de 2012 y principios de 2014. Las entrevistas se llevaron a cabo a partir de un guión de entrevista semiestructurado y los contactos se establecieron a partir de la técnica de la bola de nieve. El sexo, la edad, el tiempo de residencia en Barcelona y la nacionalidad fueron las variables básicas establecidas para la selección de las personas entrevistadas, aunque se intentó ampliar al máximo la tipología de los perfiles humanos para recoger opiniones y experiencias de personas con diferentes situaciones personales. 
Las entrevistas, que duraron un promedio de una hora, se estructuraron a partir de tres ejes temáticos (académico/laboral, social y geográfico), lo cual permitió profundizar en cuestiones tan diversas como las motivaciones para decidir estudiar y residir en Barcelona, las opiniones sobre el programa de estudios de doctorado, las transiciones laborales y personales, las experiencias cotidianas en la ciudad, la vinculación con el país de origen y los planes de futuro.

Al finalizar la entrevista, se pedía a los entrevistados que dibujaran un mapa mental de Barcelona y se solicitaron fotografías, tanto de su lugar de origen como de Barcelona, con el fin de analizar su experiencia vivida, la apropiación personal del espacio y la memoria individual. El mapa mental indica la representación de un lugar en términos espaciales, y muestra la organización y el análisis que hacen las personas del espacio, como éste se compone por lugares familiares o relevantes y, al mismo tiempo, cómo estos lugares sirven para que los individuos se ubiquen en términos relativos y se orienten a la hora de realizar tareas o desplazamientos en el espacio (De Alba, 2004; De Castro, 1997). Por lo tanto, los mapas mentales obtenidos de las personas entrevistadas permitieron conocer con más profundidad los espacios familiares y sus espacios de ocio, así como sus rutas cotidianas y la representación que hacen de la ciudad. En cuanto a las fotografías, las personas investigadas, después de la entrevista, debían escoger imágenes de sus lugares de origen y su lugar de destino, Barcelona. Este ejercicio contenía un fuerte componente emocional ya que suponía la elección de una imagen que tuviera un significado especial para ellos (su familia, sus paisajes cotidianos, algún momento de su vida particularmente emocionante, etc.). Los entrevistados tenían que enviar por correo electrónico sus fotografías y añadir una breve explicación del porqué de la elección. Así como señalan Maresca y Meyer (2015), la fotografía como apoyo a la entrevista permite explorar valores, creencias o actitudes de las personas e introducir las imágenes como catalizadoras de la memoria y de la verbalización. Asimismo, tal y como señalan Guell y Ogilvie (2015), las fotografías pueden producir una información muy rica para complementar las narraciones obtenidas con el uso de técnicas cualitativas más tradicionales, como son las entrevistas.

El colectivo analizado es muy homogéneo, lógicamente, en cuanto a niveles formativos, y el abanico de edades abarca desde los 25 hasta los 35 años. El tiempo de residencia también está muy acotado, ya que se entrevistaron estudiantes que, al menos, hubieran residido en la ciudad un año y que estuvieran realizando estudios de doctorado en el momento de la entrevista, aunque su llegada a la ciudad se podía haber debido a otros factores (por ejemplo, estudiar un máster). Las personas entrevistadas fueron informadas del objetivo de la investigación y se les aseguró que los datos se tratarían de forma confidencial. Por ello, en este artículo, siempre se usan pseudónimos y no se mencionan las universidades donde se desarrollan los estudios de doctorado.

El perfil de las 23 personas entrevistadas es de 14 mujeres (ocho latinoamericanas y seis europeas) y nueve hombres (siete latinoamericanos y dos europeos), con edades comprendidas entre los 25 y los 35 años. De este total, 20 de 23 tenían pareja en el momento de la entrevista, resaltando que nueve de estas parejas eran de distinta naciona- 
lidad a la suya. Otro patrón homogéneo: todas comparten piso, ya sea con la pareja o con amigos/as o conocidos/as, y llevan un promedio de tres años y medio residiendo en Barcelona. Para muchos de estos jóvenes no es la primera experiencia migratoria fuera de su país de origen: 11 personas habían vivido en otro país previamente (desde un mes hasta seis años), mayoritariamente por motivo de estudios. Sobre sus perspectivas de futuro, buena parte de los latinoamericanos/as quieren regresar a su país de origen, ya sea porque tienen la obligación de hacerlo debido a que sus becas doctorales están financiadas por los gobiernos de dichos países, o porque saben que en América Latina será mucho más fácil encontrar trabajo en su campo de estudio en estos momentos de crisis económica en España. La mayoría de los europeos/as entrevistados, por su parte, expresan su deseo de continuar viviendo más tiempo en el extranjero y pedir becas postdoctorales para ampliar estudios en cualquier país del mundo.

\section{III. ¿MIGRACIÓN POR ESTUDIOS?}

El grupo de estudiantes de doctorado muestra motivaciones de migración muy dispares. Contrariamente a lo que se pudiera pensar, sólo una minoría, y particularmente los europeos/as, tiene trazada una línea académica clara, enmarcándose el doctorado en una universidad de Barcelona dentro de un proyecto académico con unos contornos bien definidos. Para los latinoamericanos/as, el doctorado fue, más bien, una opción con la que se encontraron, por ejemplo después de haber abandonado los estudios por un tiempo, y responde más a un deseo de cambio de vida, que a la voluntad de profundizar en su carrera académica, al menos en un primer momento. Una vez tomada la decisión, no obstante, el doctorado parece encauzar a la mayoría de los entrevistados hacia la carrera académica, aunque algunos pocos mencionan otras posibilidades laborales de cara al futuro. Estaríamos ante carreras académicas dilatadas por cuestiones laborales, pero sin una vocación clara desde el inicio. La persona se "encuentra" con unos estudios de postgrado y decide emprenderlos teniendo en cuenta otras cuestiones personales y profesionales. En cambio, para otros, la carrera académica estaba clara, desde el principio, como opción profesional, aunque también se aplaza la decisión de estudiar un doctorado por motivos económicos. Esta espera se traduce en una inserción laboral temprana y acotada en el tiempo. Es el caso de dos jóvenes colombianos que trabajaron a la espera de una beca para estudiar el doctorado: uno en un call center (tras acabar un máster en Suecia) y otro como operario en la construcción.

Este patrón, de dilación de la carrera académica, que es mayoritario entre los entrevistados/as latinoamericanos/as, se da también para algunos europeos/as. Como es el caso de Helena, que llegó a Barcelona siguiendo a su novio catalán (se conocieron en Italia) y que se vio obligada a adaptar sus estudios universitarios en la universidad escogida por ella. Sin embargo, el resto de europeas y europeos entrevistados siguen un patrón muy definido: Durante sus estudios de grado o postgrado en su país de origen, solicitan becas de intercambio de la Unión Europea para estudiar y trabajar en una universidad de 
Barcelona y, por diversos motivos, principalmente la satisfacción con la experiencia vital y la oportunidad de solicitar (y obtener) una beca de doctorado deciden quedarse en la ciudad.

Entre los europeos/as entrevistados, por tanto, se encuentran las pocas trayectorias académicas "puras", sin inserción laboral previa, o con inserciones limitadas a prácticas profesionales. Pero, incluso en el caso de estas trayectorias, como la de Marie (una estudiante franco-canadiense, que decidió estudiar relaciones internacionales en un máster compartido entre una universidad de París y otra de Londres, y que actualmente realiza el doctorado en Barcelona), el hecho de escoger una universidad de Barcelona no responde tanto a la calidad de la misma, sino a decisiones relacionadas con el deseo de vivir en la ciudad, que se percibe como cosmopolita, pero al mismo tiempo apegada a la tradición y con dinámicas de barrio o vecinales muy marcadas.

En definitiva, los motivos que nuestro grupo de entrevistados/as consideran para emprender una migración son básicamente dos, no necesariamente antagónicos. Uno sería más académico y profesional: el interés por continuar estudiando y especializarse en un ámbito del conocimiento concreto en una universidad (situada además en una ciudad imaginada como muy atractiva, como veremos más adelante) que cumple con sus expectativas, desde un punto de vista formativo, ya que consideran que un mayor grado de especialización comporta un mayor reconocimiento y oportunidad para la promoción laboral. El otro motivo, relacionado con el anterior, sería de carácter más personal: el reto de vivir solos/as en otro país (a excepción de dos jóvenes chilenos y un ecuatoriano que llegan casados) y desarrollar una transición hacia la vida adulta.

\section{ETAPA DE TRANSICIÓN VITAL Y DIFERENCIAS DE GÉNERO}

En el mundo actual, la emancipación del hogar familiar y la obtención de un salario son momentos clave en la consecución de la autonomía y la autoestima personal, aunque la precariedad en el trabajo dificulte la transición hacia un nuevo hogar en muchos casos para los jóvenes. Dejar el hogar es un momento clave en el proceso de transición de las personas hacia la independencia y la vida adulta. Es un proceso complejo que puede ser definitivo o variar su duración dependiendo de factores como la mayor o menor durabilidad y estabilidad del trabajo remunerado o del tiempo transcurrido en un hogar de transición compartido con amigos o compañeros de estudio o trabajo (Hopkins, 2010). Una persona adulta asume, en principio, la responsabilidad de sus acciones, de tomar decisiones autónomas y ser independiente económicamente.

Esta transición, en el caso de las personas migrantes, implica la adaptación a un nuevo país y a una nueva realidad social, así como la construcción de nuevos sentidos de pertenencia. Como señala Ley-Cervantes (2012), los sentimientos de pertenencia, incluyendo aquellos relacionados con la construcción de un nuevo hogar en un país, en principio, extranjero, no son sólo experimentados a través de lo fijo y lo estable, sino que también pueden alcanzarse en condiciones de movilidad y temporalidad. Los sentidos de 
pertenencia se construyen en el caso de los migrantes cualificados a través de múltiples experiencias cotidianas, rutinas y hábitos desarrollados en el nuevo lugar habitado (Ortiz \& Mendoza, 2008).

De forma significativa, una buena parte de las personas entrevistadas se emancipa del hogar familiar en el momento que migran a Barcelona para realizar estudios de postgrado. En general, esta emancipación se vive de forma muy positiva, ya que se considera un período de desarrollo vital y de crecimiento personal, así como un proceso imprescindible para llegar a la edad adulta (Holdsworth, 2009). Cabe destacar que más mujeres que hombres expresan abiertamente lo que significó para ellas separarse de sus familias y empezar una nueva vida lejos del hogar. La independencia económica aparece, sin lugar a dudas, como un factor importante en el proceso de emancipación pero otros aspectos, como administrar sus propios recursos económicos, compartir piso con otras personas o responsabilizarse de los quehaceres domésticos, resultan también determinantes a la hora de explicar el proceso de emancipación. Las mujeres jóvenes expresan mucho más abiertamente que los hombres las emociones relacionadas con esta etapa de transición, donde a pesar de continuar estudiando (como en la infancia y adolescencia) ya no lo hacen con la ayuda de los padres (con alguna excepción), sino con financiación propia y viviendo fuera del hogar familiar. De la misma forma que los resultados obtenidos por Kennedy (2010) en las entrevistas realizadas a jóvenes comunitarios y postgraduados residentes en Manchester, las personas entrevistadas en nuestro trabajo, especialmente las mujeres, muestran emociones positivas por haberse "redescubierto", "crecido como personas", "desarrollar su propia identidad" y "sentirse felices" en la transición hacia una nueva etapa de sus vidas. Martina resume estos sentimientos con las siguientes palabras:

"En México la gente es muy cerrada. Te preguntan que por qué no estás casada. Ya por tener 31 años y no estar casada, eres una 'quedada'. Y yo ya era de ideas sobre el aborto, temas de equidad de género, tema de matrimonio, de hijos, de derechos, de exigencia, de política, de cultura muy diferente a mis amigos en mi país (...) Yo es que aquí aprendo mucho. Me encanta, me encanta conocer, me encanta saber (...). Y yo a veces llego allá con ideas y me ven como un bicho raro. Cada vez me siento más alejada”. (Martina, 31 años, México).

Un sentimiento de libertad acompaña el proceso de emancipación del hogar familiar y, en algunos casos también, el distanciamiento de la sociedad de origen. Haber crecido y vivido en una ciudad pequeña o percibir la sociedad de origen como más cerrada se contrapone a las experiencias de vivir en una ciudad más grande con una sociedad más diversa desde el punto de vista cultural, "más relajada" y "más informal".

Tradicionalmente, para las mujeres, la emancipación del hogar familiar se asociaba al momento de contraer matrimonio. Actualmente dicha emancipación llega de múltiples formas, siendo el caso que nos ocupa, la ampliación de los estudios en el extranjero, una de ellas. Curiosamente, en el caso de nuestros entrevistados, el matrimonio es un momento clave para la consecución de una mayor estabilidad y madurez personal, aunque no de emancipación del hogar familiar, que ya se había realizado previamente. 
Es el caso de un estudiante ecuatoriano, que también cuenta con nacionalidad italiana, que se casa con su novia, antes de emigrar a Barcelona, para que ambos puedan tener las mismas oportunidades laborales. Este hecho burocrático, sin embargo, se vive como una apuesta personal y profesional, de madurez; un momento de ruptura con la vida de soltero. En términos parecidos, vive José Luis su experiencia matrimonial. Este entrevistado, que se casó con un chico catalán gracias a la nueva ley de matrimonios homosexuales en España, considera este trámite como decisivo para sentirse a gusto en esta nueva etapa vital.

De la experiencia en el extranjero como estudiantes de doctorado, las personas entrevistadas subrayan ante todo el crecimiento y el enriquecimiento personal que sienten a partir de las experiencias cotidianas y las relaciones de amistad forjadas durante su estancia. En efecto, los estudiantes son sujetos complejos atentos a una multiplicidad de intereses más allá de la obtención conocimientos específicos relacionados con su campo de estudio. Son simultáneamente miembros de una familia, ciudadanos de un determinado país o/y trabajadores. En la intersección de estas múltiples esferas y posicionalidades, se desarrollan sus vidas (King \& Raghuram, 2013).

\section{COTIDIANIDADES EN LA CIUDAD DE BARCELONA}

Todos los entrevistados/as resaltan la atracción de Barcelona y la valoran como una ciudad dinámica, con una gran calidad de vida, y un importante patrimonio cultural y arquitectónico. Barcelona aparece ante la mirada atenta y crítica de los hombres y mujeres jóvenes como una ciudad cosmopolita, multicultural, rica en matices, cómoda, vibrante y segura.

“[Es] una ciudad bonita, que lo tiene todo y te da opción para todo, una ciudad organizada, limpia, cuidadosamente diseñada y planificada para atrapar y cautivar el corazón de quienes la visitan, con montañas, playas y paisajes inigualables... una ciudad cosmopolita”. (Carolina, 30 años, Colombia).

En la misma línea, pero centrándose en aspectos de su vida cotidiana, Margarida, una joven brasileña de 31 años, dibuja en su mapa mental los aspectos más positivos de Barcelona, de acuerdo con su opinión. En él, representa imágenes relacionadas tanto con sus actividades académicas (aulas de su universidad y biblioteca municipal), como con el uso del espacio público (parques, playa, terrazas al aire libre). También resalta, en el mapa, la movilidad segura y sostenible (representado por el Bicing, transporte de uso público y compartido de la bicicleta) (fig. 1). El mapa sintetiza sus cotidianidades de forma clara, estudio y ocio, y su forma de entender la ciudad entendida en términos positivos; una ciudad que ofrece servicios municipales (biblioteca, bicicletas, universidades), espacios públicos de calidad (playa, parques) y permite el uso del espacio público (terrazas) a cafeterías y bares. Estas terrazas, tan distintivas de las ciudades europeas, son muy apreciadas por Margarida, que resalta en su entrevista que no son frecuentes en su ciudad de origen. 


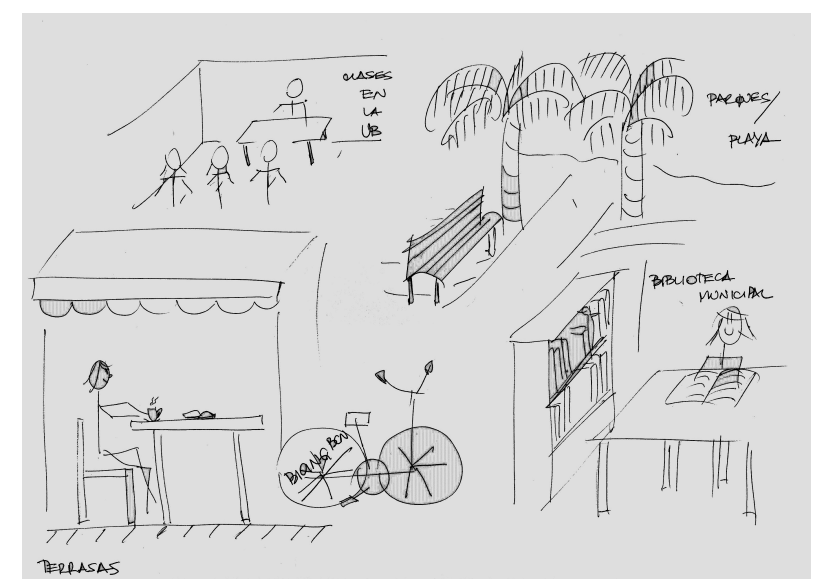

Fig. 1 - Mapa mental de Barcelona de Margarida (31 años, Brasil).

Fig. 1 - Mental map made by Margarida (31 years old, Brasil).

Los microterritorios, los barrios, son referencias importantes en la vida cotidiana de las personas entrevistadas, independientemente del área geográfica de residencia de los entrevistados. Es el lugar donde desarrollan su experiencia geográfica en la ciudad; hecho que se observará en los mapas mentales que dibujan de la ciudad. El barrio emerge como una escala privilegiada para conocer las prácticas cotidianas y los recursos materiales y relacionales a partir de los cuales las personas organizan su vida. La vida cotidiana está conectada con los lugares donde las mujeres y los hombres viven, trabajan, consumen, se relacionan con otras personas, construyen identidades, hacen frente a la rutina o la desafían. Más allá de la imagen turística de Barcelona, estos jóvenes viven la ciudad a través de donde residen o frecuentan en el tiempo libre; perciben su diversidad cultural, valoran la proximidad de los servicios y los comercios, la comodidad del transporte público, captan la identidad de los barrios (por ejemplo, a través de sus fiestas o mercados) y aprecian sentirse seguros/as y tranquilos/as, cuando pasean por la ciudad.

En efecto, la ciudad de Barcelona es un calidoscopio multicultural que, sin embargo, conserva el sentimiento de barrio y una fuerte personalidad, que da cohesión cívica al entramado social. Entre los numerosos discursos que subrayan la visión cosmopolita de la ciudad, Helena, de nacionalidad italiana, resalta su multiculturalidad y las posibilidades de relacionarse con gente de diferentes etnias, culturas y lenguas. La multiculturalidad no se contradice con una cierta vida de barrio y con el anonimato que da vivir en una ciudad grande. Barcelona tendría así el tamaño perfecto que permite ambos sentimientos.

Las comparaciones con las ciudades de origen son constantes, afirmando, en la mayoría de los casos, que la calidad de vida es más satisfactoria en Barcelona que en la ciudad de origen. Pero, mientras los europeos/as subrayan, con agrado, cuestiones relacionadas con un cierto estilo de vida, la tranquilidad de vivir en una ciudad "habitable" y los servicios de calidad (exceptuando un joven polaco que la encuentra un poco agobiante, llena de tráfico y con escasos espacios verdes); los latinoamericanos/as subrayan la comodidad 
y facilidad de desplazarse en transporte público, en bicicleta o caminando por la ciudad (comparado con la dificultad y el tiempo dedicado a desplazarse de un sitio a otro en ciudades tan extensas como Bogotá, Ciudad de México o Santiago de Chile) y la seguridad percibida en la ciudad (en comparación con la inseguridad objetiva y subjetiva de sus ciudades de origen).

Concretamente, en las narraciones de las mujeres, la comodidad y la seguridad que sienten en Barcelona juegan un papel relevante a la hora de opinar muy satisfactoriamente sobre la ciudad y el desarrollo de su vida cotidiana. Llama la atención que, al igual que en una investigación realizada en Ciudad de México con un grupo de migrantes cualificados españoles (Mendoza \& Ortiz, 2006), las formas de vestir de las mujeres se modifican según la percepción de seguridad que transmita el espacio; de esta forma, sobre todo las mujeres latinoamericanas, comentan reiteradamente que visten más "libremente" en Barcelona que en su lugar de origen, porque "aquí cada uno va a su bola (hace lo que quiere)" (Daniela, 34 años, Colombia).

"Mi ciudad es pequeña y allí todo el mundo se conoce. Te cohíbes con muchas cosas de hacer. Aquí [en Barcelona] nadie te conoce. Aquí cambias el chip. Es mi vida y nadie tiene por qué opinar ni decir nada. Y el hecho de no estar con los papás, de alguna manera, te hace más libre y más responsable. Me he vuelto mucho más responsable que estando allá... que si comprar, que si la comida... allá no, allá abría la nevera y siempre había comida. Libre y más responsable”. (Daniela, 34 años, Colombia).

Cuando se habla de Barcelona o Cataluña, y sus características sociales y culturales surgen, de forma recurrente, comentarios sobre la lengua y la identidad catalanas. En el momento de llegar a la ciudad, algunos entrevistados/as se sorprenden de que la lengua catalana sea un vehículo de comunicación en todos los ámbitos de la sociedad. Tras la primera sorpresa, este hecho no resulta ser un obstáculo para su integración social. Aunque son pocos los que declaran hablarlo normalmente (sólo una entrevista, con un joven colombiano, se desarrolló en catalán), la mayoría dice entenderlo después de pasar unos meses en la ciudad y de haber realizado cursos básicos de catalán y atendido clases en esta lengua. Una minoría, no obstante, ven en la lengua catalana una barrera, interpuesta por la población local, que dificulta su integración social.

"Con Barcelona, me pasó algo muy curioso. Era un completo ignorante de la realidad catalana, al punto de que vine a saber que existía la lengua catalana a tres meses de venir. Llegar aquí fue fascinante, descubrir todo lo relativo a la cultura catalana". (José Luis, 30 años, Colombia).

\section{FOTOGRAFÍAS PARA RECORDAR DE “ALLÎ" Y DE "AQUÎ" Y MAPAS MENTALES DE BARCELONA}

Una vez realizada la entrevista, se pedía a las personas entrevistadas que enviasen una fotografía del lugar de origen y del lugar de destino que considerasen significativas, por 
cualquier razón, y que explicasen por escrito los motivos de la elección de cada una de ellas. Las fotografías complementaron los resultados obtenidos en las entrevistas semi-estructuradas y permitieron, al igual que en otras investigaciones (Lombard, 2013; Young \& Barrett, 2001), acceder a espacios y lugares no previstos previamente en la investigación. De las 21 personas entrevistadas, 10 de ellas enviaron las fotografías y lo hicieron por correo electrónico. De las 29 fotografías analizadas, la mayoría (17 de ellas) muestran paisajes rurales y urbanos, otros monumentos, espacios públicos u otras realidades del lugar de origen y de destino; y solamente en seis de ellas aparecen personas, ya sean familiares o amistades.

Las fotografías donde aparecen personas, ya sean ellas mismas, familiares y amigos/as son realizadas por tres mujeres, aunque una cuarta evoca a través del paisaje al hermano y a los amigos de infancia. Para Valeria (31 años, México) las razones son evidentes:

“Están ahí las personas de mi familia que más amo y representan lo más importante en mi vida (mis padres, mi abuela, mi hermana, mi pareja y unos tíos), además que me recuerdan mucho las reuniones familiares donde siempre la pasamos tan bien por la comida, la plática, en ocasiones la cantada (ponerse a cantar) o el baile. Para mí, el núcleo familiar es relevante porque es ese motor que siempre te ayuda a echar para adelante, son los que incondicionalmente siempre están contigo en las buenas, en las malas y en las peores, su apoyo en todo aspecto ha sido importante, sobre todo ahora a la distancia es cuando más extrañas estos momentos". (Valeria, 31 años, México).

Daniela (34 años, Colombia) envía también fotografías de su familia en un domingo cualquiera en casa de sus abuelos donde solían reunirse para comer y estar juntos, y Carolina (30 años, Colombia) expresa a través de imágenes de su ciudad de origen, paisajes y monumentos los vínculos entre su pasado y su presente, siendo la familia, nuevamente, un elemento central en sus recuerdos:

"La familia es uno de los componentes más fuertes y representativos de todas las personas que vamos al exterior a realizar estudios... es una conexión que en vez de romperse se hace más fuerte y más importante y que tarde o temprano te hace regresar a tu país, a pesar de que los catalanes son grandes y magníficas personas poseen una cultura muy diferente a la nuestra, sobre todo en lo relacionado a festividades. Te confieso que una de las épocas más difíciles de nuestra estancia eran las festividades de Navidad. Esos días eran días muy tristes y preferíamos viajar y no permanecer en Barcelona”. (Carolina, 30 años, Colombia).

Otros entrevistados escogen paisajes para representar sus recuerdos en su lugar de origen. Nina (29 años, Eslovenia), por ejemplo, escoge mostrar una fotografía de su pueblo porque "representa mi infancia con mi hermano y amigos que la pasé jugando entre agua, mar y casitas abandonadas". Y para representar su etapa en Barcelona fotografía un cielo con nubes y el ala de un avión "es la foto que hice durante un viaje de Barcelona a Eslovenia, representa mi vida volando, mi libertad, energía y ambición que he ganado viviendo aquí en Barcelona" (fig. 2). 


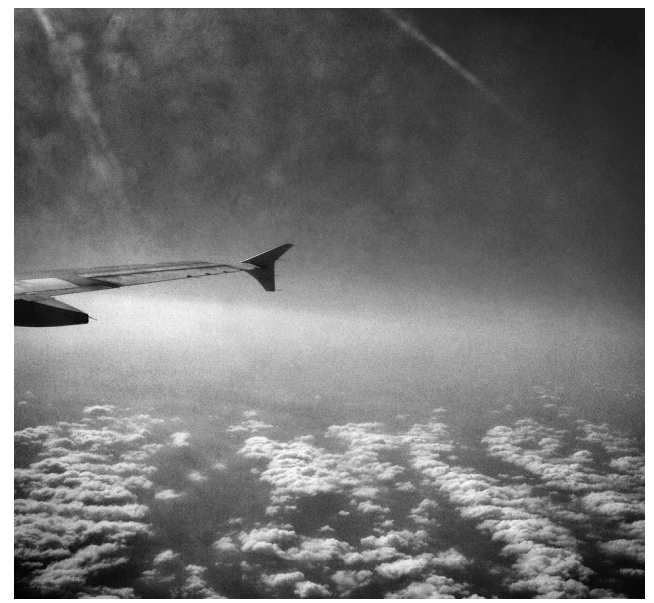

Fig. 2 - Fotografía tomada por Nina (29 años, Eslovenia).

Fig. 2 - Photo taken by Nina (29 years old, Slovenia).

Carlos, un joven brasileño, elige presentar dos fotografías de su ciudad natal, Río de Janeiro, que muestran la "gran desigualdad" de su país. En una aparece una persona recogiendo basura en un vertedero con el fondo del Corcovado (fig. 3) y en la otra unos policías caminando con los fusiles bien agarrados con un niño en primera línea mirándolos. $\mathrm{Al}$ respecto, Carlos comenta: "Las fotos que elijo de Río son las que indican la gran desigualdad de mi país, [desde] la política pública (en el caso de la foto de los militares) hasta la gente empobrecida. Como te comenté antes, aunque las clases acomodadas en Brasil piensen que estos problemas afectan solamente a los más pobres, yo tengo muy claro que su repercusión corrompe incluso la propia comprensión que tenemos sobre qué es la sociedad".

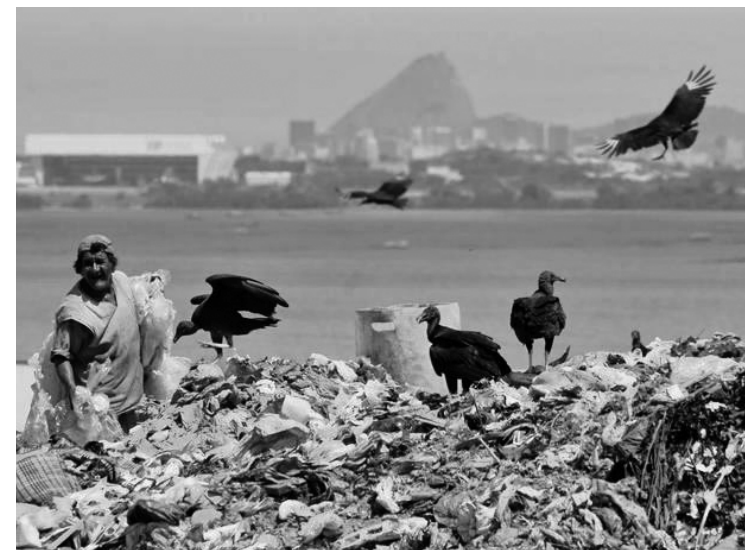

Fig. 3 - Fotografía tomada por Carlos (29 años, Brasil). Fig. 3 - Photo taken by Carlos (29 years old, Brasil). 
Carlos opina de Barcelona que "es una ciudad en que la realidad social es más justa que la brasileña. Soy consciente de que, al fin y al cabo, ambas sociedades son desiguales. Pero los niveles de desigualdad son mucho más grandes en mi país". Las fotografías que elige de la ciudad muestran un fuerte contraste con las de su lugar de origen. En este sentido, y retomando el hilo argumental de las cotidianidades, las experiencias geográficas, como elementos que ayudan a entender la integración social del colectivo de estudiantes en las sociedades de destino, este entrevistado subraya el uso y la apropiación del espacio público en Barcelona como uno de los aspectos que más valora de la vida en la ciudad. Para ello, muestra dos espacios de Barcelona donde se ven personas disfrutando del aire libre durante el día (carrera de bicicletas en la ciudad) y la noche (gente sentada en una explanada del castillo de Montjuïc viendo una película, figura 4).

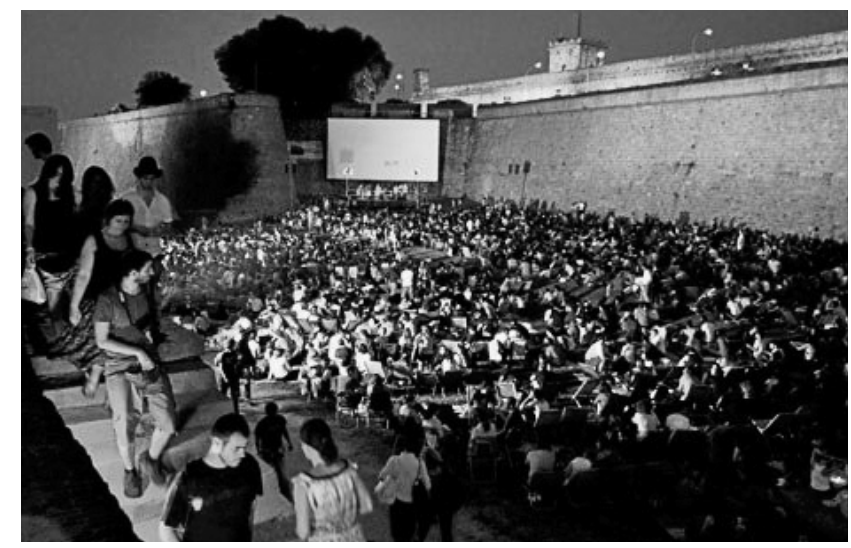

Fig. 4 - Fotografía tomada por Carlos (29 años, Brasil).

Fig. 4 - Photo taken by Carlos (29 years old, Brasil).

Enrique (31 años, Chile), por su parte, explica la elección de una fotografía donde se pueden observar un río, unas montañas y una balsa, y de esta forma la describe (fig. 5):

"Corresponde a la ciudad de Aysén [Chile], en el extremo sur del país. Por razones de trabajo viajé mucho a esa zona y tuve la oportunidad de vivir un tiempo cerca de esa ciudad. Elegí esta foto porque fue en ese lugar donde tomé la decisión de realizar el doctorado fuera del país. La gente, el paisaje, el clima y la tranquilidad de ese lugar representan la mejor motivación que dispongo para volver a mi país y especialmente a vivir a esa ciudad".

La elección de esta fotografía responde, por tanto, a la toma de una decisión vital en su vida, de la que se siente particularmente orgulloso. En un sentido parecido, otra entrevistada, Flavia (31 años, Italia) muestra una de las playas de la ciudad con dos edificios emblemáticos de la ciudad en el fondo de la imagen. La fotografía escogida evoca su vida en el lugar de origen, dado que la playa "es el lugar que, dependiendo donde voy, me recuerda mi primera ciudad y que siempre me hace sentir como en casa (...). Además 
desde hace años mi trabajo y mi investigación están enfocados en el entorno costero. Es como un hilo rojo. La costa es lo que siempre me acompañará en la vida y en el mundo". Estos elementos del paisaje de las ciudades de destino que recuerdan a los lugares de origen y la vida cotidiana que los migrantes realizaba previamente (ese "hilo rojo" que menciona la entrevistada) también se ha visto en otras investigaciones que han utilizado mapas mentales y recursos visuales en general (véase, por ejemplo, Mendoza, 2006, que aborda el colectivo mexicano en Albuquerque, Nuevo México).

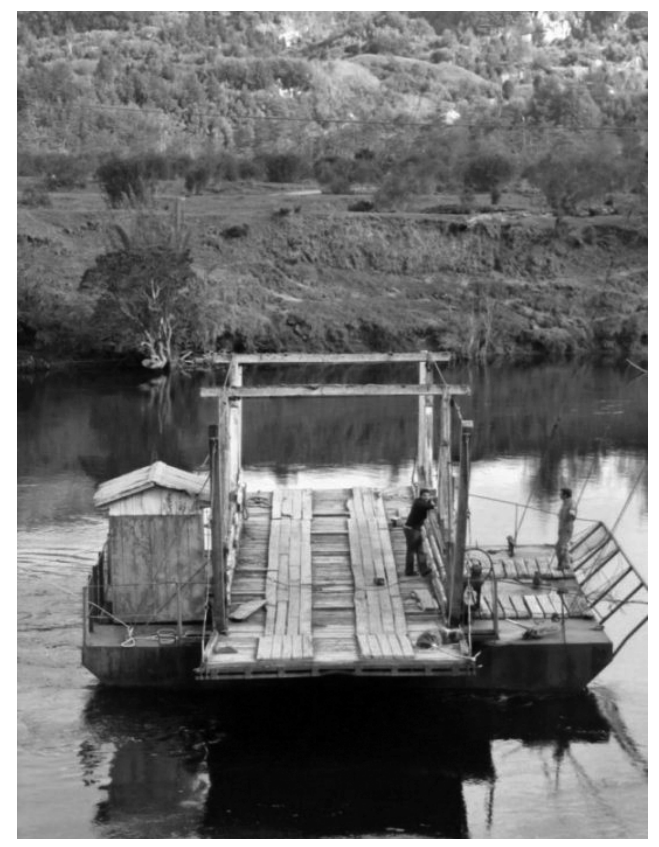

Fig. 5 - Fotografía tomada por Enrique (31 años, Chile).

Fig. 5 - Photo taken by Enrique (31 years old, Chile).

En un sentido diferente, varios entrevistados escogen una fotografía muy similar para mostrar qué significa para ellos Barcelona. Álvaro (27 años, México), por ejemplo, toma una fotografía desde el parque Güell donde obtiene una panorámica general de la ciudad. Aquí se ve una de las torres del parque y, en segundo plano, la ciudad con el mar al fondo y dos rascacielos (Hotel Arts y edificio Mafre) situados en primera línea de mar y que en los últimos años han llegado a estar presentes en el skyline de la ciudad. Comenta al respecto: "Disfruto mirar la ciudad, su estructura, el color rojo y el mar" (Álvaro, 27 años, México). Otro edificio modernista de Gaudí, la Sagrada Familia, es fotografiado también desde el parque Güell por Daniela (34 años, Colombia): "porque es lo primero que vio de la ciudad y le gusta mucho" (fig. 6). Y nuevamente, para otro entrevistado, este monumento es el que mejor representa su estancia en Barcelona: "nunca pensé que iba a vivir muy cerca de la Sagrada Familia" (Enrique, 31 años, Chile). 


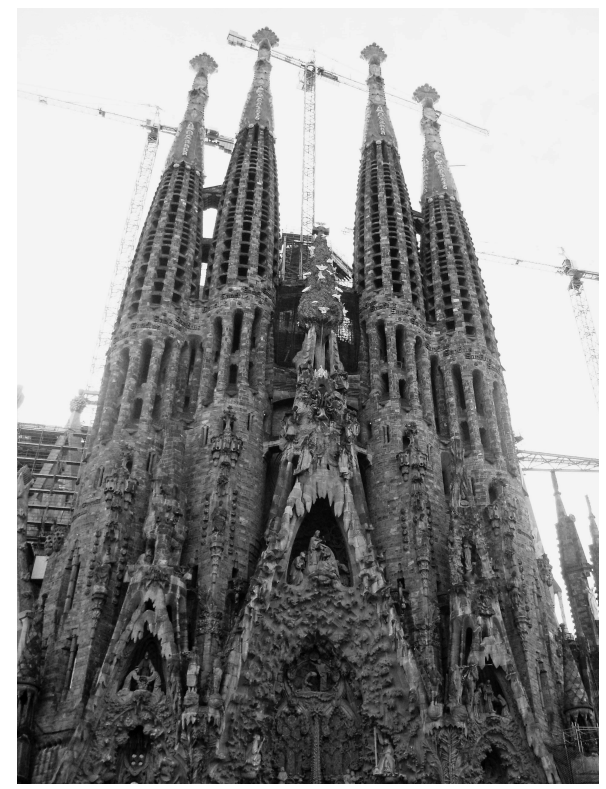

Fig. 6 - Fotografía tomada por Daniela (34 años, Colombia).

Fig. 6 - Photo taken by Daniela (34 years old, Colombia).

La mayoría de los entrevistados, como Manuel (31 años, Portugal), afirma que "yo no soy muy bueno dibujando", ante la demanda del investigador y la investigadora de este trabajo para que dibujasen Barcelona según su imagen mental de la ciudad. Sin embargo, todos acabaron aceptando dibujar en un papel blanco la ciudad donde vivían. Unos lo hacían con trazos seguros, otros con pinceladas inseguras, con líneas gruesas o finas, con más o menos detalle, con nombres en las calles o parques o simplemente con rayas rectas o curvas. De esta forma, Manuel, mientras dibuja describe su dibujo (fig. 7):

"La Diagonal... yo no soy muy bueno dibujando... el Raval, l'Eixample ortogonal... la Sagrada Familia... los parques, Montjuïc me encanta y no lo he dibujado aquí pero me encanta Collserola, la carretera de las Aguas y las playas. Los fines de semana siempre voy a correr. De mi vida cotidiana, los barrios, los pequeños cafés, los que tengo cerca de casa, la panadería que siempre voy... son mis espacios favoritos. Como voy variando de barrio, varían. La Rambla del Poblenou... me encanta estar allí y ver a la gente pasar, tener la playa cerca...”. (Manuel, 31 años, Portugal).

Los mapas mentales de Barcelona dibujados por las personas entrevistadas están formados por líneas, cuadrados y círculos que representan respectivamente, las calles principales de la ciudad (las Ramblas, la Diagonal, la Gran Vía), los barrios de residencia (Sagrada Família, Esquerra de l'Eixample, Gràcia, Guinardó, Sants, Raval, Camp de l'Arpa y Poblenou) y los más frecuentados (Eixample, Born, Gràcia, Poblenou, Barceloneta) y los espacios públicos centrales de la ciudad, de acuerdo a su criterio (Plaza Cataluña, Plaza España o Plaza de las Glorias). La playa, el mar o la línea de costa (dibujadas 
mediante líneas onduladas) y las montañas (Montjuïc y Tibidabo, representadas por montículos) son frecuentes en los dibujos, ya que ayudan fácilmente a delimitar la ciudad y a orientarse por ella. La Sagrada Familia, además, aparece como el monumento más emblemático de la ciudad y, por ello, es el más dibujado por nuestros entrevistados. Unos dibujos son totalmente minimalistas y aparecen solamente rayas sin ningún elemento escrito (fig. 8), mientras que en otros se etiqueta el dibujo con los nombres de los barrios, las calles, las plazas y los monumentos que quieren resaltar. Solamente en tres de ellos aparecen elementos como el sol, las palmeras, las terrazas, los bancos para sentarse, un avión y personas. En general, los mapas reflejan un buen conocimiento de la ciudad y de sus barrios. El hecho de que la propia ciudad responda a una cuadrícula bien organizada, con la excepción del barrio gótico, y la ubicación de la misma, inserta entre montañas y el mar, hacen que los entrevistados tengan poca dificultad para identificar estos elementos que sirven para orientarse en la ciudad y, en consecuencia, los reflejan en sus mapas mentales.

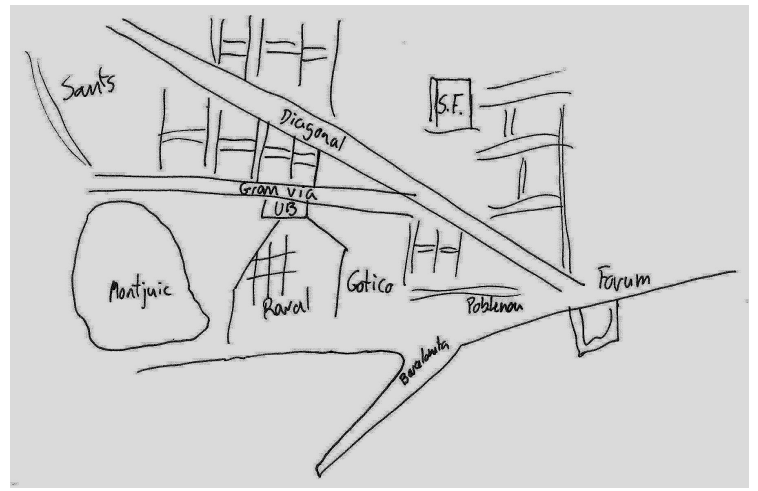

Fig. 7 - Mapa mental de Barcelona de Manuel (31 años, Portugal).

Fig. 7 - Mental map made by Manuel (31 years old, Portugal).

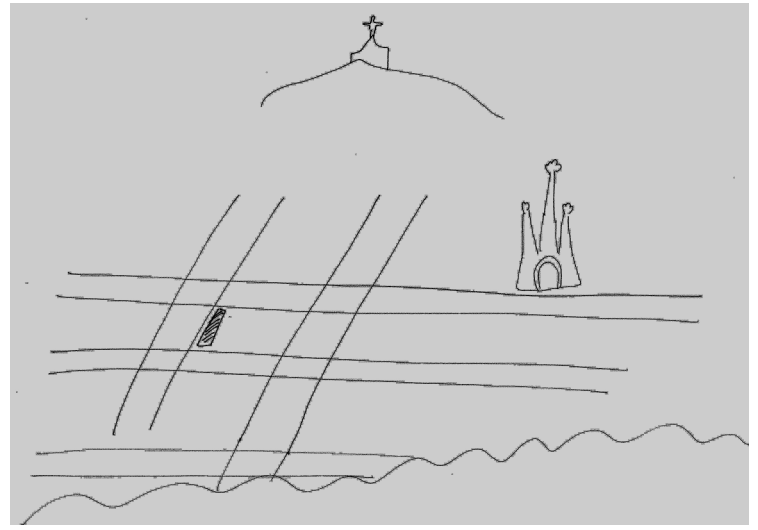

Fig. 8 - Mapa mental de Jadranka (32 años, Serbia).

Fig. 8 - Mental map made by Jadranka (32 years old, Serbia). 


\section{PROYECTO MIGRATORIO FUTURO: ¿NUEVA MIGRACIÓN?}

El proyecto migratorio de los entrevistados/as está fuertemente influenciado por la situación económica que está viviendo España, en particular, y el sur de Europa, en general. En este contexto de crisis económica (con altas tasas de desempleo juvenil y recortes presupuestarios en educación), no se ven muchas opciones laborales en el futuro en la universidad donde se están realizando los estudios de postgrado. En cambio, para muchas personas entrevistadas - y no solamente latinoamericanas -, América Latina se vislumbra como un buen destino para trabajar en la academia.

Así pues, teniendo en cuenta la situación de la economía española, cabría destacar algunas diferencias de matiz en cuanto a los proyectos migratorios. Encontramos, en primer lugar, un grupo de estudiantes de doctorado que, por el tipo de ayuda que reciben o por el plan de estudios, están condicionados a continuar su carrera profesional fuera de España. Es el caso, por ejemplo, de los latinoamericanos entrevistados que son financiados por becas o préstamos de sus lugares de origen (de Chile, Ecuador y México) y que deben regresar a su país cuando finalicen sus estudios de doctorado.

Con una perspectiva totalmente diferente, otro grupo se plantea vivir en Barcelona, pensando que las opciones laborales pueden ser mejores en el futuro y ampliando dichas opciones a otros campos profesionales. Para este colectivo, son determinantes los aspectos relacionados con la pareja y la vida en la ciudad. Este grupo valora muy positivamente la calidad de vida de Barcelona, aspecto con el cual coinciden prácticamente la totalidad de los entrevistados, y le da un peso decisivo al hecho de tener pareja catalana.

De hecho, en cuanto a proyectos de futuro, la opinión de José Luis es la mayoritaria. No se quiere dejar Barcelona, la realidad cotidiana se valora positivamente y la académica, en su mayoría también, aunque sobre este último punto no existe tanta unanimidad. La cuestión es que no se ven posibilidades laborales en la universidad catalana y, por tanto, se abren las opciones a otros países, siempre con la idea de permanecer en la academia. En este sentido, el buen momento económico, al menos en términos comparativos, de algunos países latinoamericanos plantea el regreso a los países de origen como una opción laboral atractiva:

\footnotetext{
"Mi padre me dice 'pues igual deberían venirse los dos para acá.... Mi padre no es que me quiera retener allí, él y mi madre también fue el que me dijo 'vete donde quieras. Pero ellos lo ven como 'España es muy difícil'. Mi padre dice, según sus análisis políticos, que a España le queda mucha crisis y que en estos momentos tiene más futuro de crecimiento México que España, que tiene mucho más potencial... me dice que ahí se va a estancar, se va a estancar y puede que tenga razón pero hay un detalle y es que nosotros trabajamos en investigación y en México no se hace investigación. Somos buenos, por ejemplo, en medicina, tengo que reconocerlo o en química o en bioquímica (...). Los dos [ella y su novio] estamos metidos en logística del transporte y allí esto es una porquería. Hay mucho potencial, pero a nadie le interesa”. (Martina, 31 años, México).
}

Como último patrón, encontramos un grupo minoritario de entrevistados que abordan su proyecto migratorio desde una perspectiva que podríamos calificar de transnacio- 
nal. Ven que su futuro personal y profesional no pasa por residir permanentemente en un lugar, al menos durante un cierto tiempo, sino de articular una respuesta profesional que pase por compaginar estancias de investigación más o menos largas en varios países.

\section{REFLEXIONES FINALES}

La llegada a Barcelona del colectivo de jóvenes doctorandos constituye un punto de ruptura y quiebra que, en algunos casos, coincide con la emancipación familiar. Este patrón se observa más entre los europeos que, en general, acceden a los estudios de doctorado a edades más tempranas. De esta manera, se da un triple proceso, de emancipación familiar, entrada en los estudios de doctorado y adaptación a un nuevo país. Este triple proceso es vivido, particularmente entre las mujeres entrevistadas, con mucha intensidad y con narraciones de corte positivo.

Sorprende, en un primer momento, dada importancia del paso que significa la migración internacional para la mayoría de los estudiantes de doctorado latinoamericanos, que sus motivaciones para residir en la ciudad de Barcelona no siempre están asociadas con una decisión clara de realizar estos estudios de posgrado. De hecho, entre este colectivo, no nos encontramos con trayectorias académicas "puras", sino con personas que, en algún momento de su vida se han incorporado al mercado laboral en sus países de origen y han decidido retomar la carrera académica. Sin embargo, retomando el argumento anterior de ruptura y transición que representa la migración internacional para la mayoría de entrevistados, se entiende que, para muchos, el hecho de emigrar se relacione con momentos cruciales en transiciones hacia la edad adulta, por ejemplo, una ruptura sentimental, y no tanto con un deseo explícito de continuar los estudios. Por otro lado, algunos pocos entrevistados experimentan el proceso inverso: toman decisiones vitales en su vida personal, por ejemplo, deciden casarse, ante la eventual emigración a España para realizar estudios de doctorado.

$\mathrm{Al}$ margen del momento en que se tomó la decisión de seguir los estudios de doctorado, la situación académica presente se describe, en general, en términos que podríamos calificar de formación personal y éxito académico que, no obstante, se oscurece ante las perspectivas de futuro. A grandes rasgos, es destacable que se acepte la movilidad profesional y geográfica como característica del mercado laboral universitario actual. Es más, algunos consideran que su vida ya no va a pasar por residir permanentemente en un solo país, interiorizando la migración dentro de las opciones posibles a futuro, dependiendo de las condiciones laborales que puedan surgir. Además, para algunos latinoamericanos que gozan de apoyos financieros de sus países de origen, la opción de regreso a su país es clara, ya que así está estipulado en sus becas. En otros, es un regreso que quizá no es tan deseado, dada la pérdida de calidad de vida que comporta, desde su punto de vista, vivir en una ciudad latinoamericana. De todas maneras, la mayoría de los entrevistados piensan que su futuro va a estar fuera de España, dada las condiciones actuales de crisis económica y la falta de recursos de las universidades del país. 
A pesar de pensar que el futuro no pasa necesariamente por permanecer en Barcelona, la experiencia cotidiana y personal en la ciudad se valora como muy positiva, que ofrece una buena calidad de vida. De manera incuestionable el bienestar personal asociado a la calidad de vida y el lugar están íntimamente relacionados. La conexión emocional con el lugar resulta ser un componente muy significativo en el bienestar de las personas. Los vínculos afectivos con el lugar o el barrio donde se vive, se construyen a partir de diferentes vertientes, complejas y dinámicas. Las personas entrevistadas muestran un fuerte arraigo al lugar donde viven debido a las emociones positivas y a las muchas actividades rutinarias, experiencias cotidianas y eventos significativos. Desde esa perspectiva, la ciudad de Barcelona se ofrece como un calidoscopio vital de múltiples aristas que permite una gran variedad de experiencias e intercambios. Entre estos intercambios, se encuentra la formación de nuevos hogares, dado que la mayoría de los entrevistados/as encuentra pareja en Barcelona y decide emprender la cohabitación en la ciudad.

Finalmente, cabe decir que el uso de métodos visuales, las fotografías y los mapas mentales, ha permitido complementar los resultados obtenidos en las entrevistas orales. La riqueza en los matices obtenidos en cuanto a sus recuerdos del lugar de origen y a sus experiencias y expectativas en la sociedad y ciudad de destino se han dado gracias al uso de fotografías realizadas por las mismas personas entrevistadas y a los mapas mentales dibujados al final de la entrevista por estas.

\section{AGRADECIMIENTOS}

Los dos autores agradecemos mucho estos comentarios ya que han mejorado significativamente el artículo.

\section{REFERÊNCIAS BIBLIOGRÁFICAS}

Baláz, V. \& Williams, A. M. (2004). Been there, done that': International student migration and human capital transfers from the UK to Slovakia. Population, Space and Place, 10 (3), 217-237.

Beech, S. E. (2015). International student mobility: the role of social networks. Social and Cultural Geography, 16 (3), 332-350.

Castles, S. \& Davidson, A. (2000). Citizenship and migration: Globalisation and the politics of belonging. London: Macmillan.

Collins, F. L. (2010). International students as urban agents: International education and urban transformation in Auckland, New Zealand. Geoforum, 41 (6), 940-950.
Conradson, D. \& Latham, A. (2005). Friendship, networks and transnationality in a world city: Antipodean transmigrants in London. Journal of Ethnic and Migration Studies, 31 (2), 287-305.

De Alba, M. (2004). Mapas mentales de la Ciudad de Mexico: Una aproximacion psicosocial al estudio de las representaciones sociales. Estudios Demográficos y Urbanos, 19 (1), 115-143.

De Castro, C. (1997). La geografía en la vida cotidiana: de los mapas cognitivos al prejuicio regional. Ediciones del Serbal, Barcelona.

Favell, A. (2001). Migration, mobility and globaloney: metaphors and rhetoric in the sociology of globalization. Global Networks, 4 (1), 389-398. 
Favell, A. (2008). Eurostars and Eurocities: Free movement and mobility in an integrating Europe. Oxford: Blackwell.

Guell, C. \& Ogilvie, D. (2015). Picturing commuting: photovoice and seeking well-being in everyday travel. Qualitative Research, 15 (2), 201-218.

Holdsworth, C. (2009). 'Going away to uni': Mobility, modernity, and independence of English higher education students. Environment and Planning A, 41 (8), 1849-1864.

Hopkins, P. (2010). Young people, place and identity. London: Routledge.

Kennedy, P. (2010). Mobility, flexible lifestyles and cosmopolitanism: EU postgraduates in Manchester. Journal of Ethnic and Migration Studies, 33 (3), 465-482.

King, R. \& Ruiz-Gelices, E. (2003). International student migration and the European 'year abroad': Effects on European Identity and subsequent migration behavior. International Journal of Population Geography, 9 (3), 229-252.

King, R. \& Raghuram, P. (2013). International student migration: Mapping the field and new research agendas. Population, Space and Place, 19 (2), 127 $-137$.

Leung, M. W. H. (2013). 'Read ten thousand books, walk ten thousand miles': geographical mobility and capital accumulation among Chinese scholars. Transactions of the Institute of British Geographers, 38 (2), 311-324.

Ley-Cervantes, M. (2012). Home-making strategies of Mexican middling migrants. Tesis doctoral dirigida por Liliana Suárez Navaz. Madrid: Universidad Autónoma de Madrid.

Lombard, M. (2013). Using auto-photography to understand place: reflections from research in urban informal settlements in Mexico. Area, 45 (1), 23-32.

Maresca, S. \& Meyer, M. (2015). Compendio de fotografía para uso de sociólogos. Barcelona: Edicions Bellaterra.
Mendoza, C. (2006). Transnational spaces through local places: Mexican immigrants in Albuquerque (New Mexico). Journal of Anthropological Research, 62 (4), 539-562.

Mendoza, C. \& Ortiz, A. (2006). Hacer las Américas: Migrantes españoles de alta calificación en la ciudad de México. Documents d'Anàlisi Geogràfica, 47, 93-114.

Ortiz, A. \& Mendoza, C. (2008). Vivir (en) la Ciudad de México: Espacio vivido e imaginarios espaciales de un colectivo de migrantes de alta calificación. Latin America Research Review, 43 (1), 113-138.

Raghuram, P. (2013). Theorising the spaces of student migration. Population, Space and Place, 19 (2), 138-154.

Sheller, M. \& Urry, J. (2006). The new mobilities paradigm. Environment and Planning A, 38 (2), 207 $-226$.

Smith, M. P. (2001). Transnational urbanism: Locating globalization. Malden: Blackwell.

Smith, M. P. \& Bakker, M. (2008). Citizenship across borders: The political transnationalism of El Migrante. Ithaca: Cornell University Press.

Staniscia, B. (2012). Mobility of students and atractiveness of universities. The case of Sapienza University of Rome. International Review of Sociology, 22 (2), 245-258.

Stephen, L. (2007). Transborder lives: Indigenous Oaxacans in Mexico, California, and Oregon. Duke University Press, Durham.

Urry, J. (2007). Mobilities. Cambridge: Polity Press.

Waters, J. \& Brooks, R. (2011). 'Vive la différence?': The 'international' experiences of UK students overseas. Population, Space and Place, 17 (5), 567-578 .

Wiles, J. (2008). Sense of home in a transnational social space: New Zealanders in London. Global Networks, 8 (1), 116-137.

Young, L. \& Barrett, H. (2001). Adapting visual methods: action research with Kampala street children. Area, 33 (2), 141-152.

i Una primera versión del artículo fue presentado como comunicación oral en el Decimocuarto Encuentro de Geógrafos de América Latina "Reencuentro de saberes territoriales latinoamericanos" celebrado en Lima (Perú), del 8 al 12 de abril de 2013. 